\title{
"Dispensamos o suplicante in defectu coloris": em torno da cor nos processos de habilitaçáo sacerdotal no bispado do Rio de Janeiro (1702-1745)
}

\author{
Anderson José Machado de Oliveira ${ }^{*}$ \\ ${ }^{1}$ Universidade Federal do Estado do Rio de Janeiro, Rio de Janeiro/ RJ - Brasil
}

\section{RESUMO}

A dispensa do "defeito da cor", proferida em benefício dos descendentes de escravos e africanos, tornou-se expressão corrente nos processos de habilitação ao clero secular ao longo do século XVIII. No entanto, seu emprego não foi natural e desprovido de sentido específico. A padronização das dispensas implicou a definição de um vocabulário que foi estabelecido a partir da experiência dos agentes eclesiásticos no contexto de uma sociedade escravista perpassada pelos valores de uma cultura política de Antigo Regime. Desse modo, a expressão passou a representar uma visão sobre as classificaçóes sociais com base na cor e possíveis concepçôes sobre as origens relacionadas à escravidão.

Palavras-chave: clero secular; catolicismo; escravidão; defeito da cor; classificação social.

\section{"We dismiss the supplicant in defectu coloris": color in the priestly licensing process in the diocese of Rio de Janeiro (1702-1745)}

\section{ABSTRACT}

Dismissal because of the "color defect" for descendants of enslaved and free Africans became a widespread feature of the licensing process for the secular clergy throughout the eighteenth century. However, the expression was neither natural nor meaningless. The standardization of these dismissals reflected vocabulary that was established based on the experiences of ecclesial agents in the context of a slave society permeated by Old Regime political culture.

DOI: http://dx.doi.org/10.1590/2237-101X02104511

Artigo recebido em 11 de maio de 2019 e aceito para publicação em 8 de março de 2020.

* Professor na Universidade Federal do Estado do Rio de Janeiro / Departamento de História, Rio de Janeiro/ RJ - Brasil. Bolsista CNPq PQ-2. E-mail: andersonoliveira.17@hotmail.com. ORCID: https://orcid. org/0000-0002-4801-5434.

$\mathrm{O}$ trecho em aspas no título se refere à sentença do bispo D. Francisco de São Jerônimo no processo de Francisco Xavier da Fonseca (1716-1723). Arquivo da Cúria Metropolitana do Rio de Janeiro (ACMRJ) Habilitaçôes Sacerdotais (HS). 
“DisPENSAMOS O SUPLICANTE IN DEFECTU COLORIS”: EM TORNO DA COR NOS PROCESSOS DE HABILITAÇÃO SACERDOTAL NO BISPADO DO RIO DE JANEIRO (I 702-I 745)

Anderson José Machado de Oliveira

Therefore, the expression came to represent a vision about social classifications based on color and conceptions about slavery-related origins.

Keywords: secular clergy; Catholicism; slavery; color defect; social classification.

\section{"Dispensamos al suplicante in defectu coloris": en torno al color en los procesos de habilitación sacerdotal en el Obispado de Río de Janeiro (1702-1745)}

\section{RESUMEN}

La dispensa del "defecto de color", manifestada en beneficio de esclavos y africanos, se volvió una expresión recurrente en los procesos de habilitación al clero secular a lo largo del siglo XVIII. Sin embargo, su utilización no fue natural y desprovista de sentido específico. La estandarización de las dispensas implicó la definición de un vocabulario que fue establecido a partir de la experiencia de agentes eclesiásticos en el contexto de una sociedad esclavista traspasada por los valores de una cultura política del Antiguo Régimen. De este modo, la expresión pasó a representar una visión sobre las clasificaciones sociales con base en el color y posibles concepciones sobre el origen relativas a la esclavitud.

Palabras clave: clero secular; catolicismo; esclavitud; defecto de color; clasificación social.

O "defeito da cor": a construção de um vocabulário processual

Aos seis dias do mês de fevereiro de 1708, o escrivão da Câmara Eclesiástica do Rio de Janeiro autuava uma petição de Francisco da Costa Maciel na qual este solicitava que se fizesse sua inquirição de genere (origens familiares) para que fosse ordenado. Na petição Francisco dizia-se um estudante pardo e livre, natural da cidade do Rio de Janeiro e filho ilegítimo do Licenciado Bento Curvelo Maciel, vigário colado da Matriz da Vila de São Paulo, e da preta crioula forra Madalena da Conceição. Era neto pela parte paterna do Capitão Antônio Curvelo, natural da Ilha de São Miguel, e de sua mulher Dona Joana do Souto, natural da cidade do Rio de Janeiro. Pela parte materna dizia-se neto de dois pretos de Angola sem nomeá-los. Ainda em sua petição, Francisco dava conta de ter alcançado um breve de Sua Santidade que o dispensava na cor e na ilegitimidade. ${ }^{2}$

\footnotetext{
${ }^{2}$ Arquivo da Cúria Metropolitana do Rio de Janeiro (ACMRJ) - Habilitações Sacerdotais (HS) - Francisco da Costa Maciel (1708-1709).
} 
“DisPENSAMOS O SUPLICANTE IN DEFECTU COLORIS”: EM TORNO DA COR NOS PROCESSOS DE HABILITAÇÃO SACERDOTAL NO BISPADO DO RIO DE JANEIRO (I702-I745)

Anderson José Machado de Oliveira

As sete testemunhas chamadas para depor na inquirição de genere $e^{3}$ referendaram em grande parte as informaçóes contidas na petiçấo. Todas disseram o conhecer, a seu pai e seus avós paternos, sem fazerem referência aos avós maternos. Nenhuma das testemunhas também atribuiu ao habilitando qualquer qualificativo de cor, embora este em sua petição se identificasse como pardo. Já no que se referia à qualificação de sua mãe, uma testemunha não a qualificou, enquanto três endossaram o que Francisco declarou dizendo tratar-se de uma "preta crioula", uma testemunha a designou como uma "crioula do Gentio de Guiné", uma outra a identificou como uma "preta do Gentio de Guiné crioula", e uma última testemunha disse tratar-se de uma "preta do Gentio de Guiné". As declaraçôes seguiram, neste processo, quase o mesmo teor, a exemplo do depoimento do Doutor Luís Machado:

[...] que sabia que o dito habilitando, por si e seus pais e avós paternos, são digo (sic) e inteiro, e legítimo cristão velho e por tal sempre foi tido, e havido geralmente de todos sem fama ou rumor em contrário, sem raça alguma de nação infecta das reprovadas em direito contra nossa Santa Fé católica; e que outrossim nunca ouviu que pessoa alguma desta família fosse presa ou penitenciada pelo Santo Ofício, e sabe que o dito habilitando náo tem defeito algum que lhe proíba às ordens que pretende mais que o defeito de Cor $[\ldots]^{4}$.

Em junho de 1708, após a oitiva das testemunhas, o vigário geral reconheceu o breve apostólico confirmando a dispensa dos defeitos da ilegitimidade e da cor. Em 1709, após a finalização da inquirição de vita et moribus (costumes) e do processo de patrimônio, Francisco da Costa Maciel recebeu todas as ordens sacras.

Dispensa semelhante alcançaria Custódio Correa ${ }^{5}$, natural da cidade do Rio de Janeiro e batizado na Freguesia da Sé. Em sua inquirição de genere, em 1717, Custódio disse ser filho legítimo de André Cardoso, homem pardo natural do Reino de Angola, e de Clemência da Silva, mulher preta natural da cidade do Rio de Janeiro. Pela parte paterna era neto de Joáo Cardoso, natural da Ilha de Sáo Miguel, e de Catarina, mulher preta do Gentio da Guiné. Identificou como seus avós maternos Gaspar e Catarina, ambos do Gentio de Guiné.

$\mathrm{Na}$ inquirição de genere de Custódio Correa foram ouvidas nove testemunhas, das quais cinco disseram conhecer o habilitando sem lhe atribuir qualquer qualificativo de cor. Oito depoentes disseram conhecer seu pai, entre os quais seis disseram tratar-se de um homem pardo. Seis testemunhas disseram conhecer sua mãe, mesmo as que não a conheceram lhe atribuíram cor; duas disseram tratar-se de uma mulher preta, quatro a designaram como preta do Gentio de Guiné, duas a identificaram como "preta do Gentio de Guiné crioula desta cidade", uma usou a referência "preta e crioula desta cidade". Com relação à avó pa-

\footnotetext{
${ }^{3}$ Os párocos deveriam convocar até 7 ou 8 testemunhas (Cf: VIDE, 2012, p. 824).

${ }^{4}$ ACMRJ - HS - Francisco da Costa Maciel (1708-1709). Grifos meus.

${ }^{5}$ ACMRJ - HS - Custódio Correa (1717-1719).
} 
"DisPENSAMOS O SUPLICANTE IN DEFECTU COLORIS": EM TORNO DA COR NOS PROCESSOS DE HABILITAÇÃO SACERDOTAL NO BISPADO DO Rio DE JANEIRO (I $702-$ I 745 )

terna ocorreu fenômeno semelhante, embora somente três testemunhas tenham dito que a conheceram, oito entre elas a identificaram como uma preta do Gentio de Guiné. Sete depoentes disseram conhecer o avô paterno. $\mathrm{Na}$ avaliação dos possíveis impedimentos que o habilitando teria para ordenar-se, a conclusão dos depoentes seguiu um padrão, a exemplo do depoimento do Padre José da Costa, capelão da Santa Casa da Misericórdia que disse tratar-se o habilitando de um cristão velho, limpo de sangue, sem parte alguma de nação infecta "e somente ter parte do Gentio de Guiné". ${ }^{6}$

O processo de Custódio torna-se ainda mais curioso quando se observa a conclusáo tirada pelo coadjutor da Freguesia da Sé. Ao encaminhar a documentação para o vigário geral, o Padre Inácio Rodrigues de Figueiredo ajuizou: “[...] sobre a limpeza do Sangue, e geração [...]; e me dissera ser Cristão Velho, e não ter fama, e rumor de Judeu, e Mourisco; e Somente disseram ser mulato [...]"

Ora, quem "disseram" mulato? De acordo com os depoimentos ninguém assim qualificou o habilitando. O vigário geral ao receber o processo solicitou a dispensa do "defeito da cor". Esta foi dada pelo bispo com o seguinte teor: "dispensamos no defeito do sangue, e da Cor para as Menores". ${ }^{8}$ Não há qualquer referência que a princípio explique aparecer no despacho do bispo a dispensa do defeito de sangue, já que os depoimentos, as conclusões do coadjutor da Sé e mesmo do vigário geral não apontavam para a tipificação clássica deste impedimento. Pode se tratar de um erro no despacho do diocesano ou de um entendimento ainda em construçáo da relaçáo entre os defeitos de sangue e cor.

O que me parece importante destacar por ora é o complexo processo de construçáo do vocabulário social de cor relacionado ao crescimento da escravidão. É preciso estar atento às temporalidades diversas da implantação da escravidão na América Portuguesa, bem como à diversidade e à difícil ou inexistente padronização do vocabulário classificatório (GUEDES, 2014, p. 129-130; PAIVA, 2015, p. 38). Parece que os designativos de cor utilizados nesses dois processos corroboram essa complexidade, já que diversas classificaçóes foram utilizadas pelos próprios habilitandos, por suas testemunhas e pelos agentes eclesiásticos.

Em relação aos próprios habilitandos essa visão múltipla de classificação também se apresentou no contexto dos processos. Enquanto Francisco Maciel autodenominou-se pardo, suas testemunhas não lhe atribuíram cor, mas o defeito da cor lhe foi imputado pela sua ascendência materna. Custódio Correa não teve cor reconhecida por suas testemunhas, mas será visto como mulato pelo coadjutor da Sé, que fez sua inferência pelo que ouviu das testemunhas que não mencionaram esse designativo específico de cor, afirmando tão somente que tinha parte do Gentio de Guiné, mas atribuindo cor ao pai, à mãe, à avó paterna e aos avós maternos. Essa miríade classificatória foi traduzida como defeito de cor no despacho do diocesano.

\footnotetext{
${ }^{6} \mathrm{Idem}$.

${ }^{7}$ Idem.

${ }^{8}$ Idem.
} 
“DisPENSAMOS O SUPLICANTE IN DEFECTU COLORIS”: EM TORNO DA COR NOS PROCESSOS DE HABILITAÇÃO SACERDOTAL NO BISPADO DO RIO DE JANEIRO (I702-I745)

Anderson José Machado de Oliveira

Com efeito, outras traduçôes seriam feitas pelos agentes eclesiásticos. Em 1716 foi iniciada a inquiriçấo de genere de Domingos Barbosa, natural da cidade do Rio de Janeiro e morador na Freguesia da Sé, filho legítimo de Lourenço Barbosa, natural de Arrifana de Souza, bispado do Porto, e Ana Vieira, natural da cidade do Rio de Janeiro. Pelo lado paterno era neto de Bento Barbosa e Joana Ribeira, ambos naturais de Arrifana de Souza. Seus avós maternos eram Matheus Luís, natural da Ilha do Faial, e Maria Rapoza, natural da cidade do Rio de Janeiro. Iniciados os depoimentos, a dúvida que se estabeleceu foi quanto às origens da avó materna, já que houve discrepância nas declaraçôes das oito testemunhas. A primeira disse que Maria Rapoza "era parda filha de preta"; a segunda que "tinha muita parte do gentio da terra"; a terceira "que tem casta de gente da terra a que chamam carijós"; a quarta e quinta que teria "parte do gentio da terra"; a sexta afirmou que "parece ser mulher parda ou que tinha casta de gentio da terra"; a sétima e a oitava que era "parda ou do gentio da terra". As temporalidades diferenciadas do avanço da escravidão, bem como sua influência na fixação do vocabulário classificatório parecem ficar bem claras nas declarações prestadas nesse processo, demonstrando uma terminologia ainda não tâo bem definida para os índios e aqueles de origem africana (GUEDES, 2014, p. 129).

Diante das dúvidas, o vigário geral solicitou ao cura da Sé que consultasse os livros de batismos e verificasse o assento de Maria Rapoza. $\mathrm{O}$ cura afirmou não ter achado o registro e informou que o mesmo teria sido feito no Colégio dos Jesuítas, solicitando a estes religiosos que verificassem nos livros da Igreja de São Cristóvão, nos quais costumavam registrar o batismo de seus escravos. Todavia, o registro fornecido também não foi conclusivo pois não fazia qualquer referência à cor. ${ }^{10}$

Ao persistir a indefinição, o vigário geral solicitou que a avó materna do habilitando viesse à sua presença e sob juramento declarasse "se tinha casta do Gentio de Guiné ou se tinha do da terra", ao que respondeu que "sua mãe dela dita Maria Rapoza era crioula do Gentio de Guiné, e que sua Avó também era crioula do Gentio de Guiné; e o pai dela depoente homem Branco". ${ }^{11}$ Parece que nesse caso, o termo "crioulo do Gentio de Guiné" estava sendo utilizado de forma a dirimir dúvidas quanto à origem de descendentes de africanos em relação à origem indígena ou do "gentio da terra". Há que se ressaltar que formalmente não havia qualquer impedimento legal para que índios ou seus descendentes fossem ordenados, ao contrário do que constava para a América Espanhola até o início do século XVII (MENEGUS; AGUIRRE, 2006, p. 61-74). No entanto, embora na América Portuguesa os índios fossem considerados livres, portanto passíveis de receberem as ordens sacras, sempre pairava a questão do gentilismo que colocava em questáo a qualidade da conversão destes (FERREIRA, 2016, p. 113). Porém, a legislação canônica nunca incorporou qualquer item

\footnotetext{
${ }^{9}$ ACMRJ - HS - Domingos Barboza (1716-1718).

${ }^{10} \mathrm{Idem}$.

${ }^{11}$ Idem.
} 
"DisPENSAMOS O SUPLICANTE IN DEFECTU COLORIS": EM TORNO DA COR NOS PROCESSOS DE HABILITAÇÃO SACERDOTAL NO BISPADO DO Rio DE JANEIRO (I $702-$ I 745 )

Anderson José Machado de Oliveira

que impedisse esse tipo de ordenação ao contrário do que se via para os descendentes de africanos. Desse modo, não parece que a avó de Domingos buscasse qualquer facilidade assumindo sua ascendência africana e sim estava reconhecendo algo que era de conhecimento de alguns membros da comunidade e que, se não declarado, poderia adiante criar maiores obstáculos na obtenção da dispensa eclesiástica. Diante da declaração de Maria Rapoza, concluiu o vigário geral que o habilitando "para requerer ordens mostrará dispensação na parte de mulato que lhe vem pela Avó materna". ${ }^{12}$

Como é possível observar, o termo mulato só aparecia agora na fala do vigário geral que, provavelmente, o inferiu da declaração de Maria Rapoza que disse ter sido seu pai um homem branco e sua mãe ter tido ascendência africana. O eclesiástico nesse caso aproximava-se da definição de Bluteau para o termo mulato, ou seja, "filha e filho de branco e negra, ou de negro e de mulher branca" (BLUTEAU, 1712, p. 628). No entanto, a dispensa requerida pelo vigário geral seria dada em outros termos pelo bispo, que no corpo do processo de vita et moribus o dispensou "da parte que participa de negro" sem referir-se ao designativo mulato. ${ }^{13}$

O uso do termo negro para caracterizar africanos e seus descendentes foi, na América Portuguesa, mais raro no nível do cotidiano, considerando-se principalmente seu emprego nas fontes paroquiais. Na América Hispânica o vocábulo foi de uso mais corrente em relação ao termo preto mais usual no Brasil (PAIVA, 2015, p. 200). De qualquer forma, mesmo considerando o caráter histórico desses termos e as possíveis mudanças de seus empregos, parece ser consenso que os termos negro, em diferenciação a negro da terra, e preto foram comumente utilizados para referir-se a escravos e forros demarcando uma maior proximidade com a ascendência africana (FARIA, 1998, p. 137-138; MATTOS, 2000, p. 17). No que tange às normativas eclesiásticas, o termo negro juntamente com o vocábulo mulato já era utilizado nas Constituiçóes Sinodais do Arcebispado de Lisboa e nas Constituiçōes Primeiras do Arcebispado da Bahia para definir os impedimentos em relaçấo ao recebimento das ordens sacras. As Constituiçóes da Bahia praticamente repetiam o texto das Sinodais mandando verificar se o candidato tinha "parte de nação hebreia, ou de outra qualquer infecta, ou de negro ou mulato” (CUNHA, 1656, p. 98; VIDE, 2012, p. 224). Desse modo, as adaptaçôes de vocabulário feitas pelos agentes eclesiásticos, no caso desse processo, adequavam-se ao prescrito nas legislaçôes canônicas que orientaram a Igreja na América Portuguesa.

Em 1713, chegavam ao Rio de Janeiro as inquiriçôes de genere que haviam sido realizadas em Lisboa nas freguesias de Santa Engrácia e de São João Batista, e na Praça de Mazagão ${ }^{14}$ em favor de Francisco Caheiro Teles. Francisco era natural da Freguesia de Santa Engrácia, onde fora batizado em 1686, filho legítimo de Paulo Caheiro e sua mulher Luiza Teles. Ao responder à requisitória para as inquiriçôes que partiu do Rio de Janeiro e apresentar a coleta

\footnotetext{
${ }^{12}$ Idem.

${ }^{13}$ Idem.

${ }^{14}$ Praça fortificada, ao norte da África, que permaneceu sob o domínio de Portugal entre 1486 e 1769.
} 
"DisPENSAMOS O SUPLICANTE IN DEFECTU COLORIS": EM TORNO DA COR NOS PROCESSOS DE HABILITAÇÃO SACERDOTAL NO BISPADO DO Rio DE JANEIRO (I $702-$ I 745 )

Anderson José Machado de Oliveira

dos depoimentos, o Prior Manoel Abreu Homem já adiantava que apurou ser a mãe inteira cristã velha sem raça alguma e que do pai disseram ser mulato em terceiro grau. ${ }^{15}$

$\mathrm{Na}$ freguesia de Santa Engrácia, cinco testemunhas foram chamadas a depor, em 1710. Três afirmaram conhecer o habilitando e seus pais e duas disseram que não o conheciam, porém conheciam seu pai. Quatro dessas testemunhas afirmaram que ouviram dizer ou sabiam que o pai do habilitando tinha "raça de mulato", embora náo soubessem precisar o grau. No geral admitiam que todos, filho e pais, eram cristâos velhos e limpos de sangue. Na Freguesia de São João Batista, terra do pai e avô paterno do habilitando, os depoimentos ocorreram um ano antes, em 1709. Os seis depoentes dessa localidade náo conheciam o habilitando, somente seu pai e seu avô. Destes, cinco afirmaram que o avô teria "raça de mulato" sem que pudessem precisar o grau certo. ${ }^{16}$

Em Mazagão, terra natal da mãe e dos avós maternos do habilitando, os depoimentos também foram ouvidos em 1709. Sete testemunhas foram convocadas, entre elas três cavaleiros fidalgos da Casa de sua Majestade e um cavaleiro da Ordem de Cristo, o que poderia indicar a inserção de sua mãe em uma rede de indivíduos de bastante projeção. Os testemunhos em Mazagáo foram unânimes em declarar que não conheciam o ordinando, mas que Luiza Teles e seus pais eram inteiros cristáos velhos e limpos de sangue sem raça alguma, uma das testemunhas afirmou que os avós maternos do ordinando eram "pessoas nobres". ${ }^{17}$

Os autos conclusivos do genere afirmaram a limpeza de sangue do habilitando e seus pais, embora o grau remoto e incerto de mulatismo que atingira o pai de Francisco. Parece que mesmo o mulatismo tendo sido considerado em grau incerto, o ordinando náo quis correr risco. Um mês após essa conclusão, em 15 de junho de 1713, o bispo dispensou Francisco "da parte de mulato em grau remoto" para prosseguir sua ordenação mediante pedido que este realizou solicitando uma dispensa ad cautela..$^{18}$ Assim como no caso de Domingos Barbosa, a dispensa do ordinário adotou o vocabulário contido na legislação canônica recorrendo ao termo mulato.

Foi no século XVII que a legislação portuguesa incorporou os termos negro e mulato como impedimentos, aparecendo estes também na legislação canônica. O Santo Ofício, a partir de 1680, incorporou a "raça de mulato" em seu rol de impedimentos (CARNEIRO, 1988, p. 55; RAMINELLI, 2015, p. 234). Não havia referências ao termo pardo nesse corpo legislativo. No nível cotidiano, pelo menos na América Portuguesa, esses dois termos não guardavam equivalência, na medida em que mulato era usado, geralmente, de forma pejorativa enquanto o termo pardo era acionado de forma positiva como constituidor de uma identidade que distinguia este grupo dos pretos e dos mulatos propriamente ditos (LARA, 2007; VIANA, 2007, p. 97-139).

\footnotetext{
${ }^{15}$ ACMRJ - HS - Francisco Caheiro Teles (1709-1713).

${ }^{16} \mathrm{Idem}$.

${ }^{17}$ Idem.

${ }^{18}$ Uma dispensa por precaução - ACMRJ - HS - Francisco Caheiro Teles (1709-1713).
} 
“DisPENSAMOS O SUPLICANTE IN DEFECTU COLORIS”: EM TORNO DA COR NOS PROCESSOS DE HABILITAÇÃO SACERDOTAL NO BISPADO DO Rio DE JaNEIRO (I 702-I 745)

Os processos de habilitação sacerdotal, assim como os processos inquisitoriais e àqueles que tratavam de dispensas de impedimentos para habilitação às ordens militares estavam eivados de referências ao vocabulário de cor e suas respectivas qualidades. Tal se deve em grande parte por se tratar de uma documentação que regulava uma possível mudança de estado e, portanto, o zelo pelo controle de transformaçóes na estrutura social exigia uma apuração e rigidez maior na explicitação dos marcadores hierárquicos, já que os progressos deveriam ser lentos e não ferir a "natureza das coisas" (HESPANHA, 2010, p. 251-273). Nesse particular guardavam uma diferença com os registros paroquiais nos quais as mençóes à cor foram raras no século XVII e começaram a tornar-se rotina a partir da primeira metade do setecentos (GUEDES, 2014, p. 153-168).

Estabelecida essa diferença, ao observar-se as habilitaçôes sacerdotais do bispado do Rio de Janeiro, percebe-se um movimento que aproximava os dois corpi documentais, ou seja, a familiarização e a definição de uma rotina para um vocabulário de cor que se estabelecia à medida que a escravidão africana avançava. Desse modo, mesmo que as referências à cor ocorressem de forma mais frequente nos processos, aquele vocabulário, entre a segunda metade do seiscentos e primeira do setecentos, estava em construçáo. Isso parece ficar evidente quando comparamos as referências de cor que se davam na fala dos habilitandos, nos depoimentos e nas sentenças de dispensas. Embora o vocabulário de cor guardasse um caráter fluído e mutável, havia por parte dos agentes eclesiásticos uma tentativa de uniformizá-lo, o que nem sempre coincidia com as falas das testemunhas dos processos.

Procurarei circunscrever melhor o contexto desses processos, de forma a poder verificar essa última afirmação. A tabela a seguir apresenta o universo do qual se parte:

Tabela 1 - Distribuição \% das solicitações de habilitações referentes aos "homens de cor" (1702-1745)

\begin{tabular}{|c|c|c|c|}
\hline Bispos & $\begin{array}{c}\text { Total de } \\
\text { solicitaçóes por } \\
\text { período }\end{array}$ & $\begin{array}{c}\text { No de solicitaçóes } \\
\text { referentes aos } \\
\text { "homens de cor” }\end{array}$ & $\begin{array}{c}\text { \% de solicitaçóes } \\
\text { referentes aos } \\
\text { "homens de cor” em } \\
\text { relaçáo ao total }\end{array}$ \\
\hline $\begin{array}{c}\text { D. Francisco de São } \\
\text { Jerônimo (1702-1721) }\end{array}$ & 347 & 37 & 10,7 \\
\hline $\begin{array}{c}\text { D. Frei Antônio de } \\
\text { Guadalupe (1725-1740) }\end{array}$ & 83 & 1 & 1,2 \\
\hline $\begin{array}{c}\text { D. Frei João da Cruz } \\
\text { (1741-1745) }\end{array}$ & 27 & 1 & 3,7 \\
\hline Totais & 457 & 39 & 15,6 \\
\hline
\end{tabular}

Fonte: ACMRJ - HS (1620-1958)

Os dados levam em consideraçấo os três governos episcopais da primeira metade do século XVIII. Foi nesse período que ocorreu uma maior regularidade na fixaçáo dos bispos. 
“DisPENSAMOS O SUPLICANTE IN DEFECTU COLORIS": EM TORNO DA COR NOS PROCESSOS DE HABILITAÇÃO SACERDOTAL NO BISPADO DO Rio DE JANEIRO (I $702-$ I 745 )

Anderson José Machado de Oliveira

Não estão sendo considerados os períodos de vacância, pois durante estes não se encontrou nenhum processo que dizia respeito aos "homens de cor". Porém, mais do que isso, impóe-se o fato que a diferença nos quantitativos dos processos esteve relacionada com políticas episcopais diferenciadas. D. Francisco de São Jerônimo foi mais pródigo no estímulo às ordenaçôes sacerdotais, o que também acabou impactando um maior número de solicitaçóes provenientes dos chamados "homens de cor". Seus sucessores adotaram política mais rigorista em relação à questão, considerando tanto as ordenaçóes no geral quanto em relação a grupos específicos (OLIVEIRA, 2015, p. 415-442). Além desses fatores, foi nesse período que a escravidão africana ganhou maior importância nas regiōes abrangidas pelo antigo bispado do Rio de Janeiro. ${ }^{19}$

Considerando o universo de 39 processos referentes aos "homens de cor", constata-se que quanto ao recebimento de ordens encontrou-se a situação expressa no quadro abaixo:

Quadro 1 - Recebimento de Ordens pelos “homens de cor” (1702-1745)

\begin{tabular}{|c|c|}
\hline Ordens & $\mathbf{N}^{\mathbf{~}}$ \\
\hline Todas até Presbítero & 27 \\
\hline Subdiácono & 1 \\
\hline Menores & 5 \\
\hline Não identificado* & 6 \\
\hline Total & 39 \\
\hline
\end{tabular}

* O processo não permite concluir se houve o recebimento pelo seu estado precário ou por estar incompleto. Fonte: ACMRJ - HS (1620-1958)

As ordens canônicas estavam divididas em menores e maiores. As menores comportavam quatros graus (ostiário, leitor, exorcista e acólito) e eram, em geral, recebidas em conjunto. As ordens maiores comportavam três graus (subdiácono, diácono e presbítero), sendo que para essas a legislaçáo canônica exigia idades mínimas: 22 anos para subdiácono, 23 para diácono e 25 para presbítero. Antes do recebimento das ordens menores existia a prima tonsura que, embora não tivesse o caráter de sacramento como as ordens, já assinalava a passagem para o estado clerical conferindo ao seu receptor as isençôes e imunidades canônicas (PAIVA, 2012, p. 168-169), o que, na prática, representava privilégios de foro e isençôes do pagamento de impostos.

De acordo com o Quadro 1, a maioria dos habilitandos foi inserida no corpo clerical, sendo que a maior parte obteve todas as ordens sacras até o presbiterato, podendo confessar, dizer missas e ser nomeado pároco. Nos 39 processos foi possível encontrar em 27 deles as dispensas que diziam respeito ao impedimento de cor. O quadro abaixo faz referência ao vocabulário utilizado nas dispensas.

\footnotetext{
${ }^{19}$ Até 1745 a área do bispado abrangia os territórios do sul da Bahia, Goiás, Mato Grosso, Espírito Santo, Minas Gerais, Rio de Janeiro, São Paulo, Paraná, Santa Catarina, Rio Grande do Sul e Colônia do Sacramento.
} 
“DisPENSAMOS O SUPLICANTE IN DEFECTU COLORIS”: EM TORNO DA COR NOS PROCESSOS DE HABILITAÇÃO SACERDOTAL NO BISPADO DO Rio DE JANEIRO (I $702-$ I 745 )

Anderson José Machado de Oliveira

Quadro 2 - Vocabulário utilizado nas dispensas em relação à cor (1702-1745)

\begin{tabular}{|c|c|}
\hline Vocabulário & $\mathbf{N}^{\circ}$ de referências \\
\hline Defeito da cor & 17 \\
\hline Gente/Raça/Casta/Parte de mulato & 5 \\
\hline Parte de negro & 2 \\
\hline Descendência/sangue de pardo & 2 \\
\hline Ser neto de um preto & 1 \\
\hline Total & 27 \\
\hline
\end{tabular}

Fonte: ACMRJ - HS (1620-1958)

Observa-se que mais da metade das dispensas fazia menção ao "defeito da cor", embora essa terminologia não fosse a única. No entanto, de acordo com os casos que foram apresentados, em contraposição ao vocabulário geral utilizado por ordinandos e por suas testemunhas, parecia haver um esforço do poder eclesiástico em uniformizar a terminologia estabelecendo o defeito da cor com um padrão classificatório para tratar com os habilitandos descendentes de africanos e escravos. Resta, portanto, questionar como esse tipo de dispensa foi tornando-se rotina na prática do poder eclesiástico.

De acordo com a legislação tridentina, na Sessão 23 do Concílio que tratava do sacerdócio, não havia qualquer impedimento à ordenação de descendentes de africanos e escravos. ${ }^{20}$ O rol dos impedimentos aparecia com mais clareza nas legislações sinodais. As Constituições Sinodais do Arcebispado de Lisboa, aprovadas em 1640, e que vigoraram no Brasil até a promulgação das Constituiçóes Primeiras do Arcebispado da Bahia, em 1707, colocavam como impedimento para promoção às ordens sacras ter "parte de nação hebreia, ou de outra infecta, ou de negro ou de mulato" (CUNHA, 1656, p. 98). O texto é praticamente o mesmo reproduzido nas constituições baianas, embora estas fossem mais rígidas, pois exigiam que esses impedimentos fossem verificados já quando da pretensão ao recebimento das ordens menores (VIDE, 2012, p. 224). Em tese as constituiçôes lisboetas admitiam clérigos in minoribus tonsurados sem que passassem por provas de impedimentos, o que pelas constituiçôes da Bahia era vedado.

O quadro delineado confirma as observações de Figueirôa-Rêgo e Olival quanto ao peso das questões locais na definição das classificações e distinções sociais com base na cor no império português. Para esses autores o zelo das elites locais por pressóes classificatórias fez com que, por vezes, no reino a tolerância à ascendência de cor fosse maior que em outras partes do império (FIGUERÔ-RÊGO; OLIVAL, p. 121 e 139).

\footnotetext{
${ }^{20}$ Biblioteca Nacional de Lisboa - http://purl.pt/15158 - Determinaçôes do sagrado Concílio Tridentino que devem ser notificadas ao povo por serem de sua obrigação e se hão de publicar nas paróquias. Lisboa: Francisco Correa, 1564.
} 
"DisPENSAMOS O SUPLICANTE IN DEFECTU COLORIS": EM TORNO DA COR NOS PROCESSOS DE HABILITAÇÃO SACERDOTAL NO BISPADO DO Rio DE JANEIRO (I $702-$ I 745 )

Anderson José Machado de Oliveira

Nas constituiçôes lisboetas a definição das irregularidades para a obtenção das ordens sacerdotais bem como o seu exercício já era fundamentada na ideia do defeito, o que se expressava no Título LII - Da irregularidade que nasce do defeito (CUNHA, 1656, p. 561). No Título LXXII - Da dispensação das irregularidades - as constituiçóes baianas previam que, nas irregularidades nascidas dos defeitos, somente o sumo pontífice poderia dispensar ou conceder aos bispos essa prerrogativa. Relatava-se que no caso dos bispos ultramarinos estes poderiam receber licenças de dez em dez anos do Papa para dispensar mais largamente (VIDE, 2012, p. 589-590). As sinodais baianas faziam referência às faculdades decenais que eram concessôes especiais da Santa Sé aos bispos na América Ibérica desde o século XVI. Entre essas faculdades, conferia-se aos diocesanos o poder de dispensar de impedimentos relacionados à ordenação sacerdotal, aos impedimentos matrimoniais, além de conceder indulgências e outros privilégios. O jesuíta Simão Marques publicou, em 1749, a obra Brasilia pontificia, na qual analisou cada uma dessas faculdades concedidas ao bispo do Rio de Janeiro, em 1725 (SOUZA, 2014, p. 187).

De acordo com as constituiçóes baianas, os defeitos estavam entre as irregularidades, as quais eram impedimentos que inabilitavam às ordens. Embora nas Constituiçôes não houvesse uma menção explícita ao "defeito da cor", penso ser correto interpretar que ele era deduzido do que se definia como irregularidade por defeito da origem que "é aquela por que os escravos são irregulares" (VIDE, 2014, p. 585). Essa referência à escravidão como definindo defeitos de "nascimento e estado" também já estava presente nas Sinodais de Lisboa (CUNHA, 1656, p. 562).

$\mathrm{Na}$ interpretação das faculdades decenais, precisamente na faculdade que dizia respeito à dispensa das irregularidades para o recebimento das ordens sacerdotais, Simão Marques definiu tais irregularidades como certa incapacidade moral para receber as ordens eclesiásticas e exercê-las em função de alguma impropriedade proveniente de culpa ou qualquer outro defeito. Afirmava que poder-se-ia contrair irregularidades por: $1^{\circ}$. defeito da alma (dementes, furiosos, epiléticos, iletrados, neófitos ou recém convertidos); 2º. defeito do corpo (cego, surdo, mudo, coxo, hermafrodita, notadamente feio, corcunda, leproso, paralítico, gigante, pigmeu); $3^{\circ}$. por infâmia de direito (que provém de delito próprio ou dos pais ou da condiçấo abjeta da pessoa); $4^{\circ}$. por defeito de liberdade, de nascimento, de leniência (MARQUES, 1749, p. 36-38).

Parece-me que, na América Portuguesa, as referências à escravidáo já presentes nas sinodais lisboetas, juntamente com a questão do defeito da alma além da questão do defeito por liberdade e nascimento explicitados na interpretação das faculdades decenais, foram orientaçóes importantes, juntamente com as constituiçôes baianas, para definir na prática o chamado "defeito da cor" presente nas habilitaçóes sacerdotais. Com relação ao defeito da alma, existiram opinióes correntes, nas Américas Portuguesa e Espanhola, sobre a fragilidade da conversão de índios e negros que carregariam o sangue de seus ancestrais idólatras 
"DisPENSAMOS O SUPLICANTE IN DEFECTU COLORIS": EM TORNO DA COR NOS PROCESSOS DE HABILITAÇÃO SACERDOTAL NO BISPADO DO Rio DE JANEIRO (I $702-$ I 745 )

(OLIVEIRA, 2014, p. 224-225; MARTÍNEZ, 2008, p. 210-211), produzindo uma desconfiança sobre os chamados neófitos ou recém-convertidos. Quanto ao defeito por liberdade, colocava-se em questão a falta de qualidade daqueles que descendiam de escravos. Sob esses aspectos reforçava-se a ideia da classificaçáo social com base na cor definida a partir do universo da escravidáo. Com isso, valendo-se de suas prerrogativas especiais os bispos poderiam dispensar desse defeito ou colocar em validade os breves obtidos junto à cúria romana.

O paralelismo de convivência entre a legislação universal romana e as legislaçôes sinodais, além do direito dos príncipes, colocava em evidência uma das facetas das sociedades do Antigo Regime que era a pluralidade de ordenamentos. Pluralidade esta que evidenciava uma constante situação de tensóes entre poderes, já que o processo de centralizaçáo do direito canônico (PRODI, 2005, p. 135), a partir de Trento, não eliminou a influência das normas sinodais e diocesanas, conviveu com o processo de rotinização da legislação dos Estados, além da persistência da força do direito costumeiro.

A aplicaçáo do direito canônico nesse contexto se deu preferencialmente no plano das elaboraçôes casuísticas que funcionaram não só como alternativa ao direito dos príncipes como à própria legislação universal romana (PRODI, 2005, p. 299). Por outro lado, a exacerbação da casuística serviu de modelo aos demais ordenamentos jurídicos (LEVI, 2009, p. 51-59). E, no limite, a casuística também permitiu que o direito canônico se adequasse às injunçôes dos costumes locais (HESPANHA, 2010, p. 175).

A necessidade de adequação não inibia a iniciativa do poder eclesiástico de tentar interferir e deixar sua marca no processo de classificaçáo das populaçóes no interior das conquistas. A conversão dos povos e sua inserção na cristandade partia de uma perspectiva de uniformização da sociedade, ideal que aproximava a Igreja da construçáo dos mecanismos de classificação das diferenças. Nesse sentido, o vocabulário em torno do defeito da cor expressava as ideias de uniformidade e de intervenção dos agentes eclesiásticos na produção de hierarquias.

Embora as constituiçôes sinodais reconhecessem em seus textos os termos "parte de negro e de mulato", os quais aparecem em algumas dispensas, havia uma opção que foi se firmando na primeira metade do setecentos, por parte do poder eclesiástico, por uma terminologia mais abrangente e uniformizadora. A ideia do defeito da cor, associado à ascendência africana e à escravidão, cobria um leque amplo de outras classificaçôes, permitindo à instituição um melhor manejo no controle das dispensas. O defeito da cor, por exemplo, incluía os pardos que náo estavam discriminados nas constituiçóes sinodais. Desse modo, não se pode dissociar do processo de expansão da escravidão africana esse investimento na fixação de um vocabulário processual. $\mathrm{Na}$ medida em que esta se expandia impunha-se necessariamente novos desafios para classificar os povos. Os esforços da hierarquia eclesiástica convergiam nesse sentido, procurando uniformizar para melhor controlar a miríade de classificaçôes. No entanto, a profusão classificatória continuava a se fazer como os próprios processos demonstram através da fala das testemunhas e dos próprios habilitandos. 
“DisPENSAMOS O SUPLICANTE IN DEFECTU COLORIS”: EM TORNO DA COR NOS PROCESSOS DE HABILITAÇÃO SACERDOTAL NO BISPADO DO Rio DE JANEIRO (I $702-$ I 745 )

Anderson José Machado de Oliveira

A tentativa de uniformização pelo poder eclesiástico articulava uma leitura casuística, pois dava uma margem de manobra maior para se decidir sobre situaçôes individuais, nas quais poder-se-ia aplicar com maior ou menor benevolência o privilégio da dispensa, pois a generalidade da expressão "defeito da cor" prestava-se ao estabelecimento de uma modulação entre as diversas qualidades que o vocabulário de cor expunha, transformando-o segundo cada situação. A proposição em torno do defeito da cor permitia também ao poder eclesiástico expressar uma concepção sobre as origens de africanos e seus descendentes, conformando, por sua vez, uma visão sobre a própria escravidão.

\section{A cor e a questão das origens nos processos de habilitação}

Tanto no contexto dos processos de habilitação sacerdotal quanto no âmbito mais geral que abarcava a possibilidade do acesso ou não de africanos e seus descendentes a outros postos de dignidade, o impedimento da cor estava associado a uma ou mais concepçóes sobre os significados das origens relacionadas à escravidão. Desse modo, adentra-se ao campo dos discursos que legitimaram a escravidão africana à Época Moderna e como tais discursos associaram-se ao vocabulário da cor. O que a cor contava sobre a ascendência daqueles homens que a tornava um defeito?

Nos últimos anos, ao retomar essa discussão com maior fôlego, alguns historiadores (DUTRA, 2011, p. 101-114; RAMINELLI, 2012, p. 699-723) colocaram em questão as interpretaçôes de Charles Boxer (BOXER, 1981) e Maria Luiza Tucci Carneiro (CARNEIRO, 1988) que associavam os impedimentos de cor à impureza de sangue. Segundo Francis Dutra, esses estudos iriam além das evidências, agrupando negros, mulatos e gentios como pessoas de sangue impuro, realizando uma certa confusão entre impureza de sangue e herança africana (DUTRA, 2011, p. 104). O problema da herança africana estaria associado ao fato de ela significar trabalho manual e este traduzir-se em "falta de qualidade". No que tange àqueles que pleiteavam cargos ou honrarias, a "falta de qualidade" expressava a ausência necessária de nobreza por parte dos candidatos, seus pais e os dois pares de avós (DUTRA, 2011, p. 104-105). As sentenças dos processos acima citadas parecem corroborar em parte as análises de Dutra e Raminelli, ou seja, a distinção entre defeito da cor e defeito de sangue (DUTRA, 2011; RAMINELLI, 2012).

Seguindo o modelo das sentenças que foram expostas na primeira parte deste artigo, em princípio, distinguia-se o defeito da cor do defeito de sangue. Todavia, nem sempre essa distinção apareceu de maneira tão clara. Em 1710, Antônio André Ramos deu início ao processo para a obtençáo das ordens. Antônio era natural da Freguesia de São Bartolomeu de Veiros, bispado do Porto em Portugal. Era filho legítimo de João André, natural da Freguesia de São Mateus de Bunheiro, bispado do Porto, e Maria João, natural da Freguesia de 
"DisPENSAMOS O SUPLICANTE IN DEFECTU COLORIS": EM TORNO DA COR NOS PROCESSOS DE HABILITAÇÃO SACERDOTAL NO BISPADO DO Rio DE JANEIRO (I $702-$ I 745 )

Murtosa, no mesmo bispado. Pela paterna, era neto de Antônio Migueis, natural da Freguesia de Sáo Mateus de Bunheiro, e de Maria André, natural da mesma freguesia. Segundo o cura da Igreja de São Mateus de Bunheiro, Antônio Migueis era "preto filho de negro e de uma mulher branca". Sete testemunhas que depuseram no processo de genere disseram que Antônio Migueis era de cor parda, três afirmaram que era filho de um "negro legítimo". Pela materna, o habilitando Antônio André era neto de Francisco Peres e Andreza João, ambos da Freguesia de Murtosa no bispado do Porto. ${ }^{21}$

Antes de residir no Rio de Janeiro, Antônio André Ramos havia impetrado breve junto à Santa Sé para ser dispensado do defeito de sua origem. Segundo o texto do breve, expedido em 1699, o ordinando desejando ser promovido às ordens sacras não podia fazê-lo porque "tem origem de um antepassado da gente dos etíopes, ou é de cor negra" do que foi absolvido. ${ }^{22}$

A recepção do breve, em 1706, ainda na diocese do Porto, da qual era oriundo o habilitando, foi registrada pelo provisor que se disse executor de "um Breve de dispensa de defeito de sangue" que o habilitando conseguira do Papa, "sem embargo de padecer o defeito de ser Neto de um Preto"23. Ao fim do documento repete-se que se tratava de uma "sentença de aplicação de dispensaçáo de defeito de sangue a favor de Antônio André Ramos" ${ }^{24}$. O que se observa é que no breve expedido pela Santa Sé não há qualquer referência ao defeito de sangue. Por outro lado, nenhum dos depoimentos registrados no processo identificou um antepassado cristáo novo, judeu ou mouro associado ao ordinando. $\mathrm{O}$ entâo defeito somente apareceu na recepção e tradução do breve na diocese do Porto, momento em que se fez uma equivalência entre o defeito da cor e o defeito de sangue.

Aproximação semelhante a essa também pode ser observada em relação ao habilitando Bartolomeu Dias no registro do processo de genere. Originário da cidade do Rio de Janeiro, Bartolomeu era filho legítimo de Antônio Dias Simóes e Maria Lopes, naturais da cidade do Rio de Janeiro. Pela parte paterna era neto de João da Silveira, natural do Rio de Janeiro, e de Isabel Dias, identificada como uma preta do Gentio de Guiné. Pela parte materna era neto de Tomás Ferreira e Cezilia Gonçalves, naturais da cidade do Rio de Janeiro. ${ }^{25}$

Em 1702, Bartolomeu Dias conseguiu, junto à Santa Sé, breve que o dispensava não obstante as suas origens que no documento são nomeadas como relacionadas à parte paterna por ter "parente de cor mulata ou origem negra". No mesmo ano o então breve apostólico foi reconhecido e lavrado pelo vigário geral do Rio de Janeiro com o seguinte parecer: "dispenso com ele no impedimento da ilegitimidade e defeito de sangue em virtude do breve q. impetrou". ${ }^{26}$

\footnotetext{
${ }^{21}$ ACMRJ - HS - Antônio André Ramos, 1710-1711.

${ }^{22}$ Idem.

${ }^{23}$ Idem.

${ }^{24}$ Idem.

${ }^{25}$ ACMRJ - HS - Bartolomeu Dias, 1702-1708.

${ }^{26}$ Idem.
} 
“DisPENSAMOS O SUPLICANTE IN DEFECTU COLORIS”: EM TORNO DA COR NOS PROCESSOS DE HABILITAÇÃO SACERDOTAL NO BISPADO DO Rio DE JANEIRO (I $702-$ I 745 )

Outra dubiedade em relação a esse tipo de classificação se daria em um semelhante despacho do vigário geral no processo Francisco Martins da Silva. Era este natural da cidade do Rio de Janeiro, filho legítimo de Francisco Martins, homem pardo e oficial de barbeiro, e de Joana Garcia, crioula forra, ambos naturais da cidade do Rio de Janeiro. Os avós paternos do ordinando eram Manoel Martins, natural da Ilha da Madeira, e Francisca da Silva, preta do Gentio de Guiné. Os avós maternos eram Alamão Carrieyro, de nação francesa, e Maria da Costa, uma preta do Gentio de Guiné. O vigário geral, em 1712, após a oitiva das testemunhas de genere, o sentenciou limpo de sangue, mas que tinha parte de negro pelo "que náo encontra a pureza do sangue [...] sendo dispensado no defeito da cor" ${ }^{27}$

A sentença parece deixar mais nítida a ambivalência que a questão suscitava. Em 1718, agora em uma sentença do bispo, a questão cor e sangue voltava a ser intercambiada. Tratava-se do processo de Felipe da Gama, natural do Rio de Janeiro, filho ilegítimo de Manoel da Gama Senra, também natural do Rio de Janeiro, e de Mônica de Azevedo, exposta em casa de Madalena Ferreira. Na sentença, D. Francisco de São Jerônimo, em relação às pretensōes do habilitando, decretou que ele era legítimo e inteiro cristão velho, sem raça "e se lhe passara sua sentença de genere para requerer o que lhe parecer e sendo para Ordens haverá primeiro dispensa da ilegitimidade, e defeito do sangue pardo". ${ }^{28}$

Retomando a discussão proposta por Francis Dutra, que afirma que Boxer teria ido além das evidências, associando cor e defeito de sangue, o que se pode observar é que nos processos de habilitação, pelo menos na primeira metade do século XVIII, a questão ainda suscitava dúvidas. Se, na maioria dos processos analisados, a cor aparece de fato como um defeito de qualidade, isso não parece ter sido suficiente para desfazer algumas ambivalências. Nesse sentido, Boxer ter-se-ia equivocado ou percebido somente uma parte da questão? Por outro lado, as fontes priorizadas por Dutra e Raminelli são os processos de habilitação às ordens militares que corriam no reino, onde essa distinção talvez já se fizesse com maior precisão. Como alerta María Elena Martínez, no centro da monarquia espanhola os teóricos que formularam o discurso oficial da coroa já haviam decidido sobre a questão, principalmente no caso dos índios, estabelecendo a distinção entre gentilismo e impureza de sangue (MARTÍNEZ, 2008, p. 214).

Os processos que corriam nas áreas de conquistas poderiam não ter incorporado ainda totalmente os mesmos referenciais. As fontes eclesiásticas, principalmente aquelas produzidas na América Portuguesa em meio à latente questão da escravidão, podem, nesse sentido, apresentar algumas variaçóes expressando a persistência de uma visão teológica que remetia à própria discussão da incorporação dos africanos na cristandade portuguesa.

A expansão portuguesa moderna colocou em questão a definição sobre os lugares dos povos incorporados ao império dentro do discurso da evangelização. A intensidade desse

\footnotetext{
${ }^{27}$ ACMRJ - HS - Francisco Martins da Silva, 1711-1718.

${ }^{28}$ ACMRJ - HS - Felipe da Gama, 1716-1748.
} 
"DisPENSAMOS O SUPLICANTE IN DEFECTU COLORIS": EM TORNO DA COR NOS PROCESSOS DE HABILITAÇÃO SACERDOTAL NO BISPADO DO Rio DE JANEIRO (I $702-$ I 745 )

debate atingiu um ponto culminante entre o período de D. Manuel e D. João III, quando os teólogos ligados à corte disputaram em torno do papel da África e dos africanos na conquista. Pedro Margallo, um dos mais influentes teólogos da corte de D. Joáo III, acreditava que os etíopes teriam admitido heresias e falsos dogmas, observando preceitos da lei velha, equiparando-se aos costumes de outros infiéis. $\mathrm{O}$ avançar das conquistas, no entanto, foi enfraquecendo ou colocando em segundo plano esse pensamento, conduzindo à ideia que os etíopes não eram cristáos heréticos e que seus erros eram leves e poderiam ser emendados. Damião de Góes, outro importante teólogo e humanista do período, foi um dos que defendeu a absolvição e a conciliação da Etiópia, garantindo, através da missão, sua inserção na cristandade (MARCOCCI, 2012, p. 147-222).

Em termos gerais parece ter sido este o entendimento de Roma, pois em Bula do século XVI, o Papa Leão X asseverou a D. Manuel e ao bispo de Lamego, que diante da consulta que recebia deles em relação à ordenação de "Etíopes, Indios e Africanos", anuía favoravelmente, "não obstantes os defeitos de nascimento, se alguém os sofrer". ${ }^{29} \mathrm{O}$ conteúdo da bula permite, portanto, compreender as dispensas proferidas por Roma aos ordinandos acima mencionados.

A construção do sistema classificatório com base na cor, mesmo diante das controvérsias teológicas acima mencionadas, foi erguida em um ambiente ideológico no qual uma outra relaçáo importante era edificada em torno da associaçáo entre negritude e pecado. Parece-me que aí está um dos caminhos para se compreender essas ambivalências entre cor/qualidade e cor/defeito de sangue. Segundo Benjamin Braude, foi ao longo da Época Moderna que se foi fixando a história da divisão do mundo entre os filhos de Noé. Foi nesse período que ocorreu um processo de africanização de Cam, embora este ainda fosse representado como um homem branco, tendo enegrecido somente em representaçôes que se tornaram correntes no século XIX. Por outro lado, a identificação dos descendentes de Cam com os africanos e a decorrente associação entre cor da pele e transgressão/pecado fora iniciada pelos muçulmanos e assumida pelos cristáos no momento em que se engajaram mais fortemente no tráfico de escravos (BRAUDE, 1997, p. 105-109; BRAUDE, 2002, p. 112-113).

A ideia de pecado parece ser um elemento-chave no entendimento dessas associaçôes. Se o defeito de sangue, no caso dos cristáos-novos, definia-se em última instância pela associação com a heresia, no caso de africanos e seus descendentes a possível associação explicava-se pela questâo do pecado. A heresia, em face da doutrina cristâ, apresenta-se como um fator de dissidência, pois atenta contra o corpo doutrinário da Igreja, deteriorando o conteúdo julgado original da fé (RIBEIRO JR., 1989, p. 19-20). Por outro lado, se a teologia moderna colocou o pecado no centro de suas reflexôes, configurando-o como um ato de oposição do homem à vontade de Deus, também se esforçou para elaborar um discurso de interiorização da culpa, estimulando a confissão e os atos de penitência (DELUMEAU, 2003, p. 357-397). Desse modo, por meio da submissão à Igreja, aos pecadores oferecia-se a possibilidade de

${ }^{29}$ Monumenta Missionária Africana - Bula do Papa Leão X a D. Manuel I - 12/061518. 
"DisPENSAMOS O SUPLICANTE IN DEFECTU COLORIS": EM TORNO DA COR NOS PROCESSOS DE HABILITAÇÃO SACERDOTAL NO BISPADO DO Rio DE JANEIRO (I $702-$ I 745 )

Anderson José Machado de Oliveira

reconciliação e, consequentemente, de salvação. Africanos, seus descendentes e índios não estavam em tese inseridos em credos heréticos ou grandes sistemas religiosos, como o Judaísmo e o Islamismo, além de não representarem uma ameaça de contaminação, ao contrário dos cristãos-novos, que eram vistos como um perigo à pureza do cristianismo. Aqueles grupos, portanto, foram tomados como pecadores ou gentios, de forma que não era necessário combatê-los, mas simplesmente doutriná-los nos princípios da fé cristã (FIGUERÔA-RÊGO; OLIVAL, 2011, p. 137-138; MARCOCCI, 2011, p. 59).

Afastando-se a controvérsia teológica em torno de um possível comportamento herético, o defeito da cor e o defeito de sangue pareciam estruturar-se, no caso de africanos e seus descendentes, em torno da ideia do pecado ou do gentilismo. Uma associaçáo que tinha uma conotaçáo moral, pois a própria definiçấo de defeito implicava uma de suas acepçôes na ideia de "defeito moral, que se toma por qualquer vício ou paixão" (BLUTEAU, 1712, p. 34-35). Tais questôes remetiam a negritude à punição e à conversão como a superação dos vícios morais. Essa questão e também a ideia do defeito como falta de qualidade podem explicar por que a dispensa em relação ao sangue cristáo-novo era mais complicada.

De qualquer forma, no acesso ao sacerdócio, a legislação canônica local reforçava as ambivalências, pois tanto no texto das Sinodais de Lisboa quanto das Constituiçóes Primeiras, como já assinalado, estabelecia-se como critério de impedimento a equivalência entre ter "parte de nação hebreia, ou de outra qualquer infecta, ou de negro ou mulato" (CUNHA, 1656, p. 98; VIDE, 2012, p. 224). O emprego do termo nação, embora a sua gama de significados no Antigo Regime, parece, no caso do texto canônico, remeter à ideia de mácula religiosa.

O defeito da cor parecia possuir também uma compreensão religiosa, juntamente com a questão da qualidade, embora nos processos de habilitação esta última tendesse a se diferenciar da primeira. Cor era, dessa feita, uma classificação que guardava bases sociais e religiosas, o que coloca em questão certas ideias teleológicas de um processo de racialização biológica a partir da Época Moderna. Interessante notar que mesmo entre os naturalistas da segunda metade do século XVIII, como Buffon, a cor da pele era entendida como característica que se relacionava com o clima, com a alimentaçáo e com os costumes. Mesmo para Lineu as diferenças entre cores de pele expressavam-se para além da biologia, espraiando-se para tendências em torno de uma psicologia de grupo que associava às cores um conjunto de valores psíquicos e morais; uma distância ainda se estabelecia com as teorias raciais do século XIX (ROGER, 1989, p. 241-244; BARBOUJANI, 2007, p. 66), pois não haveria uma imutabilidade de características físicas transmitidas de uma geração à outra. Mesmo Francisco Bethencourt, que acredita em um processo de racialização na América Ibérica na modernidade, argumenta que a variação cromática do processo de classificação não estava assentada somente em elementos físicos, mas também mentais, não se podendo falar de "raça" como uma característica meramente física (BETHENCOURT, 2018, p. 248-250). 
“DisPENSAMOS O SUPLICANTE IN DEFECTU COLORIS”: EM TORNO DA COR NOS PROCESSOS DE HABILITAÇÃO SACERDOTAL NO BISPADO DO Rio DE JANEIRO (I702-I745)

Anderson José Machado de Oliveira

Portanto, mesmo que se possa perceber, por exemplo, algo fenotípico no emprego do termo "raça de mulato" (RAMINELLI, 2015, p. 236-237), esse uso não estava impregnado dos critérios racialistas do oitocentos. Em depoimento no processo do habilitando Francisco Caheiro Teles, uma das testemunhas - Manoel Lopes - referiu-se ao mulatismo do ordinando na forma seguinte:

Sempre ouviu dizer que o Justificante por parte do dito seu Pai tem Raça de Mulato a qual no mesmo Justificante fica já, em quarto grau o que tudo é público nesta freguesia, e fora dela e que por parte de sua Mãe é cristão velho, de limpo sangue sem Raça de Judeu Mouro Mulato, ou cristão novo nem de outra infecta nação das reprovadas contra a nossa Santa Fé Católica, E por tal foi sempre tida sem fama nem rumor em contrário, E outrossim nunca ouviu dizer que o Pai do Justificante tivesse outro defeito no sangue mais do que o já dito de Raça de Mulato $[. . .]^{30}$

A "raça de mulato", para Manoel Lopes, era um defeito no sangue, que se distinguia dos outros, mas não deixava de ser um impedimento que na sua fala assumia o viés religioso não guardando relação com qualquer outra caracterização racial contemporânea. O que se observa nos processos de habilitaçáo foi uma questão que perdurou pelo menos na primeira metade do setecentos. Como demonstra María Elena Matínez, na América Espanhola a questấo também não foi de fácil resolução. Embora a autora admita que a relação entre cor e qualidade se afirmasse, chama igualmente a atenção para o fato de que, na Nova Espanha, a inserção de índios, mestiços e negros foi pensada também a partir da ideologia da pureza de sangue e, portanto, de categorias que tinham relação com a fé e a adesão desses grupos ao catolicismo. Martínez demonstra que o discurso jurídico encampado pela monarquia espanhola tendeu a reconhecer a adesão de índios e negros à fé católica, considerando, principalmente, em relação aos índios que eles eram cristáos velhos e por isso dissociados da mancha da impureza de sangue. Todavia, ao longo dos séculos XVII e XVIII, náo faltaram escritos teológicos que defendiam posiçáo contrária, afirmando que o sangue dos ancestrais idólatras corria nas veias de índios e negros e que, portanto, estes, principalmente os últimos, poderiam ser vistos como semelhantes aos judeus, aos mouros e a seus descendentes. A ambivalência do discurso, segundo a autora, permeou o seiscentos e o setecentos, demonstrando a convivência das concepçóes que tanto associavam origem e status social quanto origem e fé (MARTÍNEZ, 2008, p. 207-224).

$\mathrm{O}$ que se pode concluir é que a questão religiosa continuou a influenciar as classificações sociais de uma forma geral, e ainda em específico àquela com base na cor. Se a falta de qualidade era algo que se foi afirmando com maior ênfase na definiçáo do defeito da cor, por outro lado, as referências religiosas não despareceram imediatamente dos processos de

${ }^{30}$ ACMRJ - HS - Francisco Caheiro Teles (1709-1713). Grifos meus. 
"DisPENSAMOS O SUPLICANTE IN DEFECTU COLORIS": EM TORNO DA COR NOS PROCESSOS DE HABILITAÇÃO SACERDOTAL NO BISPADO DO Rio DE JANEIRO (I $702-$ I 745 )

Anderson José Machado de Oliveira

habilitação, de forma a demonstrar que o referencial com base na fé não fora apagado da gramática social. Desse modo, parece que se Boxer não viu a questáo por completo, não deixou de enxergar parte dela ao chamar a atenção para a relaçáo que alguns estabeleciam entre o defeito de cor e a impureza de sangue.

A persistência das ambivalências nas classificações indica, em meu entendimento, duas questôes que me parecem fundamentais afirmar. A primeira diz respeito à tentativa da Igreja em uniformizar a ideia do "defeito da cor". A continuidade da miríade classificatória das cores, em concomitância à iniciativa eclesiástica de uniformização, impulsionava uma iniciativa da instituição para manter parte do poder discricionário na concessão do privilégio da dispensa, atribuindo-se papel importante no controle da mobilidade social, via sacerdócio, dos descendentes de africanos. Isto não deve colocar em segundo plano os arranjos em que aqueles homens estavam inseridos visando ao movimento na hierarquia. Movimento este que, na primeira metade do século XVIII, reproduzia padrôes hierárquicos no interior do próprio grupo de descendentes de escravos e libertos, diferenciando-os entre si, recriando uma dominação tradicional fundada em mecanismos paternalistas e de uma aparente estabilidade da ordem vigente. A segunda questão relaciona-se ao problema das origens, pois se a ideia de ausência de qualidade vai se afirmando como um dos elementos associados à escravidão e também à cor, há que se levar em consideraçáo que a persistência de algumas zonas ambivalentes no discurso preservavam ainda o papel da religiáo como elemento de construção das classificaçôes sociais, tornando não só mais complexo o entendimento dessas, bem como a compreensão da ideia de mestiçagem, colocando em dúvida uma antecipação excessiva ou mesmo teleológica de critérios raciais científicos que iriam ter maior desenvolvimento de fato no oitocentos.

\section{Fontes documentais}

ARQUIVO DA CÚRIA METROPOLITANA DO RIO DE JANEIRO (ACMRJ). Fundo Habilitações Sacerdotais (HS) (1620-1958).

BLUTEAU, Raphael. Vocabulario Portuguez e Latino. Coimbra: Collegio das Artes da Companhia de Jesus, 1712.

BULA DO PAPA LEÃO X A D. MANUEL I - 12/061518 - Monumenta Missionária Africana.

CUNHA, Dom Rodrigo da. Constituiçöes Sinodais do Arcebispado de Lisboa. Lisboa: na Oficina de Paulo Craesbeek, 1656.

DETERMINAÇÕES DO SAGRADO CONCÍLIO TRIDENTINO QUE DEVEM SER NOTIFICADAS AO POVO POR SEREM DE SUA OBRIGAÇÃO E SE HÃO DE PUBLICAR NAS PARÓQUIAS. Lisboa: Francisco Correa, 1564 - Biblioteca Nacional de 
“DisPENSAMOS O SUPLICANTE IN DEFECTU COLORIS”: EM TORNO DA COR NOS PROCESSOS DE HABILITAÇÃO SACERDOTAL NO BISPADO DO Rio DE JaNEIRO (I 702-I745)

Lisboa - http://purl.pt/15158.

MARQUES, Simão. Brasilia Pontificia: sive speciales facultates pontificiae, Brasiliae Episcopis conceduntu. Lisboa: Ex Typis Michaelis Rodigues, 1749.

VIDE, Sebastião Monteiro da. Constituiçóes Primeiras do Arcebispado da Bahia. São Paulo: EdUSP, 2012.

\section{Referências}

BARBOUJANI, Guido. A invenção das raças. São Paulo: Contexto, 2007.

BETHENCOURT, Francisco. Racismos: das Cruzadas ao século XIX. São Paulo: Companhia. das Letras, 2018.

BOXER, Charles R. O Império Colonial Português 1415-1825. Lisboa: Ediçôes 70, 1981.

BRAUDE, Benjamin. Cham et Noé. Race et esclavage entre judaïsme, christianisme et islam. Annales. Histoire, Sciences Sociales. 57e année, n. 1, 2002.

BRAUDE, Benjamin. The sons of Noah and the construction of ethinic and geographical identities the medieval and early modern periods. The William and Mary Quarterly, v. 154, n. $1,1997$.

CARNEIRO, Maria Luiza Tucci. Preconceito racial: Portugal e Brasil-colônia. 2. ed. São Paulo: Brasiliense, 1988.

DELUMEAU, Jean. O pecado e o medo: a culpabilização no Ocidente (séculos 13-18) - v. 1. Bauru: EDUSC, 2003.

DUTRA, Francis. Ser mulato em Portugal nos primórdios da época moderna. Tempo, Niterói, v. 15, n. 30, 2011.

FARIA, Sheila de C. A colônia em movimento. Rio de Janeiro: Nova Fronteira, 1998.

FERREIRA, Fernanda V. O clero secular no bispado do Rio de Janeiro e o múnus episcopal de D. Francisco de São Jerônimo (1702-1721). Dissertação (Mestrado em História), Programa de Pós-Graduação em História, UNIRIO, Rio de Janeiro, 2016.

FIGUIERÔA-RÊGO, João de; OLIVAL, Fernanda. Cor da pele, distinções e cargos: Portugal e os espaços atlânticos portugueses (séculos XVI a XVIII). Tempo, Niterói, v. 15, n. 30, 2011.

GUEDES, Roberto. Livros paroquiais de batismo, escravidão e qualidades de cor (Santíssimo Sacramento da Sé, Rio de Janeiro, séculos XVII-XVIII). In: FRAGOSO, João; GUEDES, Roberto; SAMPAIO, Antonio Carlos Jucá de (org). Arquivos Paroquiais e História Social na América Lusa. Rio de Janeiro: Mauad X, 2014. 
“DisPENSAMOS O SUPLICANTE IN DEFECTU COLORIS”: EM TORNO DA COR NOS PROCESSOS DE HABILITAÇÃO SACERDOTAL NO BISPADO DO Rio DE JANEIRO (I $702-$ I 745 )

HESPANHA, António Manuel. Imbecilitas: as bem-aventuranças da inferioridade nas sociedades de Antigo Regime. São Paulo: Annablume, 2010.

LARA, Silvia H. Fragmentos setecentistas: escravidão, cultura e poder na América Portuguesa. São Paulo: Companhia das Letras, 2007.

LEVI, Giovanni. Reciprocidade mediterrânea. In: OLIVEIRA, Mônica Ribeiro de; ALMEIDA, Carla Maria Carvalho de (org). Exercícios de micro-história. Rio de Janeiro: FGV, 2009.

MARCOCCI, Giuseppe. A consciência de um império. Portugal e o seu mundo (séculos XVXVII). Coimbra: Imprensa da Universidade de Coimbra, 2012.

MARCOCCI, Giuseppe. Escravos ameríndios e negros: uma história conectada. Teoria e modelos de discriminação no império português (ca. 1450-1640). Tempo, Niterói, v. 15, n. 30, 2011.

MARTÍNEZ, Maria Elena. Genealogical Fictions: limpieza de sangre, religion and gender in Colonial Mexico. Stanford: Stanford University Press, 2008.

MATTOS, Hebe Maria. Escravidão e cidadania no Brasil monárquico. Rio de Janeiro: Jorge Zahar, 2000.

MENEGUS, Margarita; AGUIRRE, Rodolfo. Los indios, el sacerdocio y la Universidad en Nueva España. Siglos XVI-XVIII. México: UNAM, 2006.

OLIVEIRA, Anderson José M. de. A administração do sacramento da ordem aos negros na América Portuguesa: entre práticas, normas e políticas episcopais (1702-1745). Lócus, Juiz de Fora, v. 21, n. 2, 2015.

OLIVEIRA, Anderson José M. de. Dispensa da cor e clero nativo: poder eclesiástico e sociedade católica na América Portuguesa. In: OLIVEIRA, Anderson José M. de; MARTINS, William de Souza (org). Dimensöes do Catolicismo no Império Português (séculos XVI-XIX). Rio de Janeiro: Garamond, 2014.

PAIVA, Eduardo F. Dar nome ao novo: uma história lexical da Ibero-América entre os séculos XVI-XVIII. Belo Horizonte: Autêntica, 2015.

PAIVA, José Pedro. Um corpo entre outros corpos sociais: o clero. Revista de História das Ideias. Coimbra, v. 33, 2012.

PRODI, Paolo. Uma história da justiça. São Paulo: Martins Fontes, 2005.

RAMINELLI, Ronald. Nobrezas do Novo Mundo: Brasil e ultramar hispânico, séculos XVII e XVIII. Rio de Janeiro: FGV, 2015.

RAMINELLI, Ronald. Impedimentos de cor: mulatos no Brasil e em Portugal c. 16401750. Vária História, Belo Horizonte, v. 28, n. 48, 2012.

RIBEIRO JR., João. Pequena história das heresias. Campinas: Papirus, 1989.

ROGER, Jacques. Buffon: un philosophe au Jardin du Roi. Paris: Fayard, 1989. 
“DisPensamos O SUPLICANTE IN DEFECTU COLORIS": EM TORNO DA COR NOS PROCESSOS DE HABILITAÇÃO SACERDOTAL NO BISPADO DO RIO DE JANEIRO (I 702-I 745)

Anderson José Machado de Oliveira

SOUZA, Evergton Sales. A construção de uma cristandade tridentina na América Portuguesa (séculos XVI e XVII). In: GOUVEIA, António Simóes; BARBOSA, David Sampaio; PAIVA, José Pedro (coord). O Concílio de Trento em Portugal e nas suas conquistas: olhares novos. Lisboa: Universidade Católica Portuguesa, 2014.

VIANA, Larissa. O idioma da mestiçagem: as irmandades de pardos na América Portuguesa. Campinas: UNICAMP, 2007. 